\title{
Virtual Artefacts to Support Negotiation within an Augmented Collaborative Environment for Alternate Dispute Resolution
}

\author{
Peter Dew \\ School of Computing \\ University of Leeds \\ Leeds, LS2 9JT, UK \\ +441133436804 \\ dew@comp.leeds.ac.uk
}

\author{
Aphrodite Galata \\ School of Computing \\ University of Leeds \\ Leeds, LS2 9JT, UK \\ +441133435767 \\ afro@comp.leeds.ac.uk
}

\author{
John Maxfield \\ School of Computing \\ University of Leeds \\ Leeds, LS2 9JT, UK \\ +441133435767 \\ max@comp.leeds.ac.uk
}

\author{
Daniela Romano \\ School of Computing \\ University of Leeds \\ Leeds, LS2 9JT, UK \\ +441133436804 \\ D.M.Romano@cbl.leeds. \\ ac.uk
}

\begin{abstract}
Commercial organisations that are in dispute will sometimes seek to settle their differences without resorting to legal proceedings through a process of structured and facilitated negotiation called Alternate Dispute Resolution (ADR). Traditionally ADR negotiations are conducted by co-locating the mediator, witnesses, supporting evidence and representatives of each party. This paper describes a novel experiment that has been conducted at the University of Leeds to investigate whether an augmented collaborative environment could provide a realistic alternative to co-locating individuals for ADR negotiations. The individuals that took part in the experiment included an experienced mediator and practising legal representatives. The augmented collaborative environment was based on a video conferencing system that was enhanced to enable virtual artefacts representing items of evidence to be blended directly into the video streams. This experiment sits within the framework of the Court 21 Project, that is seeking to identify how new technology can be used to improve the different aspects of the legal system [10].
\end{abstract}

\section{Categories and Subject Descriptors}

Novel use and evaluation of collaborative environments and their applications

\section{General Terms}

Design, Experimentation, Collaborative Working

\section{Keywords}

Remotely located negotiations, augmented reality, virtual reality, collaboration, design, evaluation.

\section{INTRODUCTION}

In commercial environments two organisations that are in dispute will often seek to settle their differences out of court through negotiation in the form of an Alternate Dispute Resolution (ADR). If successful, this process avoids the need to conduct lengthy and expensive legal proceedings and is thus a more desirable way of reaching a quick resolution for small commercial disagreements. ADR negotiations are facilitated by an independent and neutral individual, called a mediator. The mediator will ensure that each party remains fair and reasonable and that a mutually satisfactory solution is reached wherever possible. ADR negotiations are therefore a form of communication in which each party attempts to present a case designed to influence the other party's opinion. ADR negotiations are normally conducted face to face, which means bringing together the witnesses, supporting evidence, mediator, and representatives of each party in one physical location. However the time and expense incurred in co-locating all of these individuals and supporting material can sometimes diminish the benefits of conducting an ADR negotiation.

This paper describes a novel experiment that has been conducted at the University of Leeds to investigate whether an augmented collaborative environment could be used to avoid the need to collocate individuals and evidence for ADR negotiations. The augmented collaborative environment consists of a standard video conferencing system that has been modified to allow virtual artefacts, representing items of evidence, to be blended directly into the video streams.

This study sits within the framework of the Court 21 Project, that seeks to identify how new technology can be used to improve the different aspects of the legal system [10]. The project has adopted an iterative rapid prototyping methodology. Each iteration involves the construction of a realistic case study, development of a proof of concept, conducting an experiment and then collecting user feedback to evaluate the design choices made and identify further requirements for the next iteration.

The paper first presents the background work related to this experiment and then presents the case study. This is a fictitious case involving a dispute between two mineral water companies. In particular, the dispute focuses on the similarity in shape and design of the bottles in which their respective products are sold. The augmented collaborative environment that was developed for 
this work is then described and the experiment involving real users is discussed. Feedback from the users and observers of this experiment was gathered and used to evaluate the technology. The feedback is presented and analysed in some detail towards the end of this paper. The virtual artefacts were found to allow each party to make more compelling arguments by revealing important insight into the underlying shape and design of the products involved. It was also found that the formal nature of the ADR negotiation process minimised some of the problems normally encountered in video conferencing, such as loss of situation awareness and turn taking.

\section{BACKGROUND}

There is currently a wealth of tools and technologies available for supporting both synchronous and asynchronous communication in distributed environments, from e-mail, to video conferencing and telepresence. The common aim of each of these tools is to support the exchange of information, knowledge and experiences between different individuals. Technology allows this exchange to occur in a timely and efficient manner, irrespective of geographical distribution.

Over the last decade the legal profession has been gradually adopting IT for both standard administrative tasks and more specialised legal practices, such as litigation support. Advanced applications for IT and their impact on courtroom litigation have also been explored through experiments conducted by Lederer [11]. Lederer's work has investigated a wide range of applications, including the used of video conferencing to allow witnesses to appear in court from remote locations, the use of voice recognition technology to creating a textual record of the proceedings (to replace the stenographer), and the use of panoramic images and 3D animations for the presentation of evidence.

Lederer characterises legal processes and practices as a highly sophisticated form of information management [11]. Information is assembled and sorted before being brought into the courtroom for presentation. Within the courtroom various interpretations of the information are argued and the data is analysed according to prescribed legal rules.

While ADR negotiations are not strictly a legal process with a legally binding outcome, they are an important step in the pre-trial process that can be taken for minor disputes to avoid the need to proceed to full legal proceedings. If the process is to be successful it demands almost the same level of due diligence from each party in preparing the case and support evidence as a legal trial. The similarities in structure and formality to legal processes are such that skilled legal representatives are often employed to conduct the ADR negotiations.

This paper therefore investigates how to support structured ADR negotiation in a distributed environment, in which virtual artefacts are presented to support each party's case. In the context of this paper, virtual artefacts are items of evidence in an electronic form, specifically documents, pictures, movies and 3D objects extracted from a web repository and integrated within the video conferencing environment.

A number of environments have already been developed to support general negotiation processes. These include expert systems that assist in the preparation of material and arguments prior to a negotiation, decision support systems to assist both groups and individuals, and agent-based systems that can conduct certain types of negotiations on behalf of the human. A full review of the state of the art in negotiation support systems can be found in the literature $[14,16]$.

In this context the augmented collaborative environment developed for this work aims to support collaborative negotiation (and associated reasoning and decision making processes) by facilitating the structured presentation of relevant information in a distributed environment.

\section{THE ADR CASE STUDY}

Although fictitious, the case study for this experiment was created to closely model a real ADR negotiation. The case involved a dispute between two mineral water companies, one based in the UK called Faraday Ltd. and a younger company based in the US called Edison Corp. In particular, it focused on a dispute over the similarity in shape and design of the bottles in which their respective sparking mineral water products were sold. Both bottles hold one litre of liquid, are made of dark green glass, have a gold coloured cap, and exhibit a distinctive teardrop shape and similar labels, as illustrated in Figure 1.

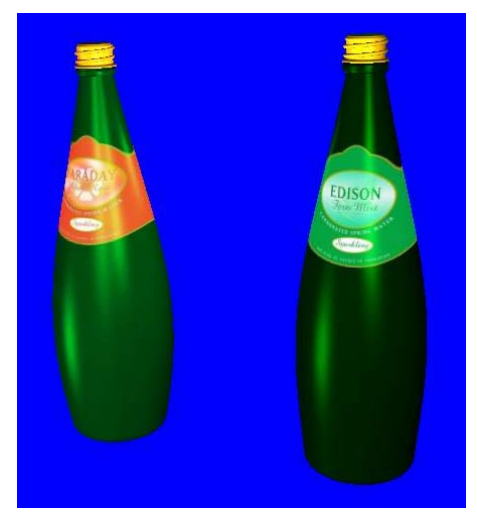

Figure 1: The Faraday (left) and Edison (right) Bottles

Faraday lodged a complaint with Edison, claiming that they had copied the design and style of their bottle in a deliberate attempt to capture some of Faraday's existing customer base. In response Edison refuted this idea, claiming that the bottles have discernable differences in both shape and colour.

Although this is a fictitious case, such disputes are fairly commonplace within the commercial world. Unless such disputes can be resolved out of court, the organisations must consider taking legal action. This can be tremendously time consuming and expense thus every effort is normally made to negotiate a solution first. This case study assumed that the companies had already mutually agreed to attempt to settle out of court by participating in an ADR negotiation with an independently appointed mediator. The study also assumes that the representatives for each organisation were given sufficient time to prepare their arguments, witnesses and supporting evidence.

Faraday's argument was that the bottles were almost identical and that Edison had infringed its copyright. They hoped to be able to convince Edison to acknowledge the similarities and modify the 
design of their bottle accordingly. Beyond the obvious similarities, the Faraday case was based on demonstrating that the dimensions of the bottles were within the manufacturing tolerances of each other. Therefore manufacturing variations could, and probably would, produce bottles with almost identical dimensions, as illustrated in Figure 2. To strengthen the case Faraday brought forward a complaint from one of their customers stating that they had mistakenly purchased the Edison product because the bottles looked so similar on the shelf in the supermarket.

In contrast Edison's case was prepared to demonstrate that there were sufficient differences between the bottles so as to invalidate any claim of copyright infringement, should Faraday choose to pursue legal action. In particular their argument hinged on being able to clearly demonstrate that the bottles had a noticeably different shape. They choose to illustrate this by placing one virtual bottle inside the other and changing its colour, as shown is Figure 2. Edison also sought to strengthen their case by compiling an independent survey of consumers, which clearly indicated that the majority of the consumers could clearly tell the difference between the products.
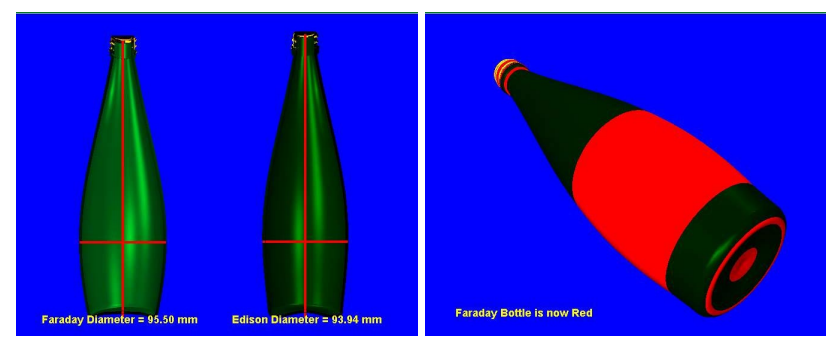

Figure 2: Comparing Dimensions (part of Faraday's case) and Shape (for Edison's case) using the Virtual Bottles.

The case study assumes that both parties agreed to conduct the negotiations remotely using an augmented collaborative environment and were asked to confirm that the virtual models were a true and accurate representation of their respective products. Each party was also given full access to the other party's evidence, including the virtual models, prior to the negotiation.

\section{AUGMENTED COLLABORATIVE ENVIRONMENT}

To support this negotiation a collaborative environment was constructed. Based on the rapid prototyping methodology adopted within the Court 21 project, the first prototype environment was configured using existing technologies, wherever possible. The environment was based a standard $\mathrm{H} 323$ video conferencing systems supporting communication over 3 dedicated ISDN pairs (up to $384 \mathrm{k}$ ). A second computer was also used to generate the virtual artefacts (bottles) using an Interactive Virtual Prototyping System (IVPS) developed through previous research at the University of Leeds [18]. A number of predefined actions and viewing positions were set up within the IVPS so that they could be quickly recalled to illustrate certain keys points made by each party during the negotiations, for example toggling the display of certain dimensions, applying cut planes to segment out particular areas of the bottles, or placing one bottle inside another.

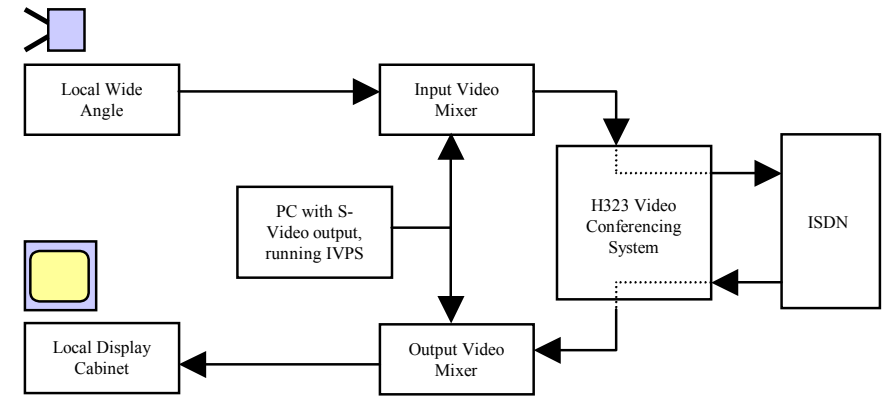

Figure 3: Blending virtual artefacts into the live video streams within the augmented collaborative environment.

The video conferencing system and IVPS were integrated using a real time video signal mixer, as illustrated in Figure 3. The virtual artefacts are all rendered using a blue background, thus allowing for a standard "blue-screen matting" approach to be used to blend the video signals. The lighting and a number of preset positions for the bottles were carefully designed so as to make the virtual artefacts appear a natural part of the scene.

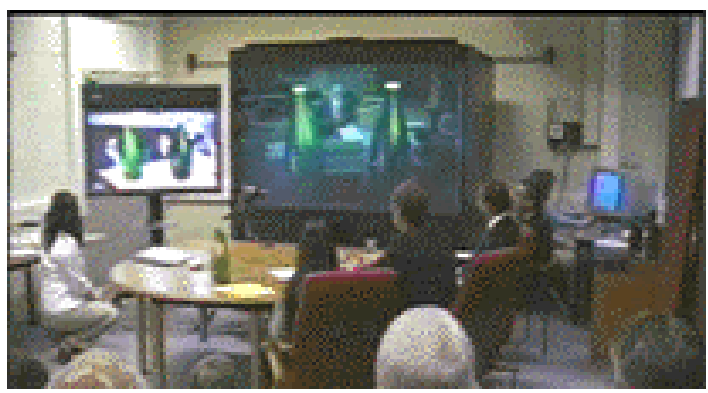

Figure 4: A view of the local displays used during the experiment as seen by the participants.

In this configuration the virtual artefacts are produced using a computer and then mixed into both the incoming and outgoing video streams, eliminating the need for an expensive graphics computer at both ends of the video conference. Therefore the environment can be used to share virtual artefacts with any H323 video conferencing system, including standard PictureTel and Polycom set top units.

During the experiment a second smaller display was connected to the outgoing video signal to allow the local participants to see the final blended image that was being sent to the remote participants, in addition to their own display, as illustrated in Figures 4 and 5. 

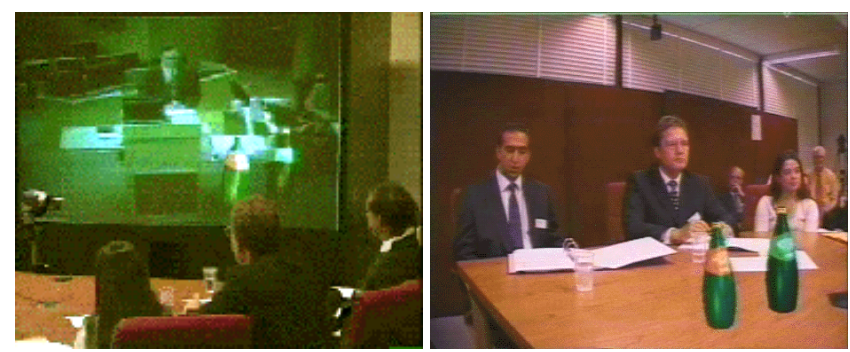

Figure 5: The local view (left) and remote end view (right)

\section{THE EXPERIMENT}

The experiment was conducted over the course of a single day and involved an experienced mediator and qualified lawyers representing both parties. Both the incoming and outgoing video streams were recorded for the entire session for later study and analysis. The lawyer for Faraday and the mediator participated from a conferencing room within the University of Leeds in the UK, while the lawyer representing Edison joined the negotiation from the William and Mary School of Law in the US. An audience of representatives from the Crown Prosecution Service (CPS) and members of the legal profession, including senior judges and magistrates, were all present in order to observe the proceedings and provide feedback at the end of the experiment.

Once the video conference call had been connected and both parties were present, the formal negotiation was initiated by the mediator, who began by first explaining the purpose of the meeting and the possible outcomes. The lawyer representing Faraday was then invited to present his argument to those present. Once complete the mediator invited the lawyer for Edison to present his counter arguments. Both parties made extensive use of the same virtual artefacts to illustrate key points within their arguments. They also drew on electronic images and documents that were blended into the incoming and outgoing video streams using the same techniques as those used for the virtual artefacts. Once complete each party was then permitted to ask questions about the other party's case. The mediator then invited both parties to state their expectations and to negotiate a mutually satisfactory solution.

\section{EVALUATION}

The ADR environment developed for this experiment made use of existing technologies where possible, such as video conferencing, the Interactive Virtual Prototyping System and online web document storage facilities. After the experiment was completed, the participants and audience were asked to provide feedback on their experience and perceptions during the negotiation. The feedback and the video footage were then studied and analysed in order to identify the strengths and weaknesses, and generate a refined set of requirements for the next phase of the work.

The participants' views were collected after the events on the $11^{\text {th }}$ September 2001. This may have resulted in a greater level of enthusiasm in favour of conducting negotiations over a video conference link, than would have previously been the case.

\subsection{Methodology}

A qualitative evaluation method was used, in order to focus on the meaning of the user's actions, rather than simply the quantity of them. This approach is more meaningful in the context of this work because it involved a real negotiation situation, rather than one in an artificial laboratory setting. The first stage involved collecting the opinions and beliefs of a selected set of participants and members of the audience with a good knowledge of matters related to law. The actual participants in the experiment were a professional mediator, an experienced UK lawyer and a Professor of Law from the USA. The audience consisted of representatives from the Crown Prosecution Service (CPS) and members of the legal profession, including senior judges and magistrates. Their observations, questions and comments after the event have been recorded and are reported.

Feedback from these individuals was elicited through structured interviews and a questionnaire containing both closed and openended questions. Beyond the actual participants mentioned above, four members of the audience agreed to take part in a more detailed study. They were aged between 33 and 55 years old. Three of the subjects were male and one was female. All subjects were familiar and experienced in difference aspects of the legal profession and all spoke English as their first language.

Due to the relatively small number of people involved in the evaluation and the nature of ADR negotiation, the results reported here have to be considered as only indicative. The word "experts" will be used in the following sections to refer to the participants in the evaluation of the experiment.

\subsection{Trust Issues}

An important question arising from the proposed solution was whether the use of this technology actually modified the result of the negotiation in any way. Put another way, did the participants trust that the environment in which they conducted the negotiation did not influence the final outcome. The work of Damian et al $[2,3]$ gives us confidence that this is unlikely to be the case. They investigated whether using video conferencing, rather than faceto-face meetings, had an impact the performance of the participants. Media effect theories [4] predict that a negotiation task should be performed better when conducted face-to-face. Contrary to expectations, Damian et al found that groups meeting face-to-face perform no better than those using video conferencing or computer support when conducting requirements negotiations. Furthermore, they identified that if the two conflicting parties were geographically separated, performance improved. All participants felt that the media was much more conducive to negotiation than a face-to-face meeting. Due to the reduced level of social awareness, participants are forced to compensate through increase verbalisation. Increasing the dialogue between the parties will give rise to more opportunities for identifying a mutually satisfactory solution.

The second area of concern was whether the outcome of the negotiation would be affected by the reduced ability of participants to read non-verbal cues as a result of technology limitations. For example the resolution of the video might make it more difficult to spot minor non-verbal signals during the communication process. Chidambaram [1] reports that the lack of socio-emotional cues associated with non face-to-face communication is transitory or time-dependent. Parties that work with each other in a non face-to-face manner on a regular basis, such as the lawyers within this experiment, will often develop relationships over time. This allows socio-emotional cues to emerge and act as effective substitutes for the cues given during a 
normal face-to face experience [12]. In our case the participants had a relatively short time to become familiar with each other, which may have affected the group's overall awareness [7].

Negotiation is a specialised form of communication that has been studied by a number of authors [13 \& 14]. For example in [6] Fisher describes negotiation as a process in which two or more parties communicate with the aim of influencing each other's decision. LiPera defines trust in negotiations with respect to predictability and co-operation, namely the ability to predict how the other party will act or react, and whether they will co-operate [12]. On-line arbitration has been discussed by Hill [8].

In our case ADR negotiations involve communication between a mediator and lawyers represented each side in the dispute. The important point here is that the protocol used for these negotiations has a clear and natural turn-taking structure, in which only one person will speak at a time. Even during questioning, the mediator ensures a strict turn taking protocol. It is believed that the formal nature of this interaction means that it should be possible to achieve a higher level of group awareness than is possible with normal less structured meetings. This proposition is supported by one expert who observed that the group's awareness was high during the ADR negotiation because it was a structured and formal process, following a prescribed turn taking protocol.

The experts were very positive about the experience. All of them felt that:

(i) The way in which the negotiation had been conducted using the augmented collaborative environment was practical.

(ii) They had confidence that the environment was rich enough for them to convey their point of view during a negotiation and did not influence the final outcome of the negotiations. There was sufficient trust established to use the virtual artefacts. Both parties were ask to agree this before the negotiation started. Furthermore they all agreed that a professional and experienced mediator would not show any unintentional bias towards a co-located participant, provided the logistics of the meeting had the consent of both parties.

(iii) The environment provided adequate support for basic interactions, and that the resulting the negotiation was as effective as one conducted face-to-face. However some of the experts observed that a video conference was too impersonal and thus felt that people would perform better due to the increased pressure of a face-to-face conflict. Such perceptions might be difficult to change.

(iv) All of the experts recognised that allowing people to participate in a negotiation from a remote location saves both time and cost. One expert noted that in order to fully realise the efficiency benefits of the technology it would be necessary to first modify the existing processes in order to make full use of the new capabilities. To change a process it is necessary to identify the new requirements, manage people's attitudes and resistance to change, promote the use of the technology, provide adequate information and training, and introduce new staff to manage the technology.

One expert reported using video conferencing actually enhanced the situation, since it forced the other participants to focus their attention completely on the statements being made and the objects in question. Another reported that familiarity between the participants appeared to increase the transparency of the technology. Therefore as the negotiation progressed they perceived the richness of the interaction to be approaching that of a face-to-face meeting.

In summary they felt that this way of conducting an ADR negotiation was practical and were confident they could trust the technology not to affect the final outcome.

\subsection{Use of Virtual Artefacts}

The ADR case study was designed to take full advantage of the virtual artefacts as items of evidence. All the experts recognised that the use of virtual artefacts enhanced the negotiation substantially. The experts all agreed that one could make a claim with the help of virtual artefacts, which could not be made any other way. They also all agreed that the virtual artefacts would be of benefit for both face-to-face and remote negotiations, since they can be used to support the arguments of either side.

However several experts indicated the real artefacts should never be completely replaced by virtual ones, since they still convey information that the virtual one cannot (e.g. weight, surface texture, rigidity). Rather the virtual and real artefacts should both be employed and used where appropriate depending on the arguments being forwarded. The virtual artefacts should be tailored for each negotiation and only used when there is an advantage in doing so over the real objects, and when all parties agree. Furthermore since some of the artefacts may be very time consuming and expensive to reconstruct as virtual models, the choice becomes one of balancing appropriate costs.

Some of the experts noted that it would have been useful if the participants had been given the ability to point to or highlight parts of the evidence during their arguments.

A key point to emerge was the degree of information sharing prior to negotiation. All experts agreed that the use of virtual artefacts should be verified and approved by both parties before the event. They also felt that being able to interact with the artefacts during the negotiation was invaluable. One expert noted that since the purpose of a negotiation was to reach a mutually satisfactory agreement, disclosing the evidence and arguments prior to the negotiation would speed up the resolution of the dispute.

Although the experts all felt it would be useful to have a common repository for all information associated with a negotiation, major concerns were raised on the security and retrieval time for such a service. One expert suggested that the on-line repository would feel more secure if placed on a non-public network with a central point of control. The use of electronic documents has been studied in a wider context, e.g. by Sherfey in [15], and many of the benefits reported in that work apply equally to ADR negotiations.

\subsection{Technology Issues}

Various comments were made about the quality of the ADR environment. The experts felt that higher resolution video should be used and that the camera positions should be rearranged to establish better eye contact between the participants. The use of a large display cabinet was seen as appropriate for situations in which an audience was present.

Three of the experts reported that they could not make out the details of the body language of the remote participant due to the relatively low resolution of the video image. They all felt that it was important to be able see the person in the video window and 
to be able to clearly read his body language, especially when the person was unfamiliar to them. Once familiarity had been established the quality of the video image was no longer perceived as problem, since they were able to pick up cues from the intonation of the voice and the body movement that was distinguishable within the video image.

The augmented collaborative environment described here integrates the virtual artefacts within a standard H323 video stream. All the experts agreed that it was equally important that they were able to see both the evidence and the remote participant at the same time. The method of superimposing the virtual artefacts on the video stream was seen as acceptable, provided that the person presenting the evidence was not obscured. All of the experts agreed that the way the artefacts were presented did not detract from the conversation or interfere with the interaction between the participants. One expert noted that an advantage of this method was that one could see what the remote participant was doing in the background, without having to look away from the evidence. Another expert suggested this could also be achieved using two separate monitors, a large rear display for the video image and a smaller front monitor for evidence.

\subsection{Efficiency}

Large distances are not the only consideration when undertaking a negotiation with video conferencing tools. One of the experts suggested that they would be in favour of desktop video conferencing for such negotiations, in order to avoid having to leave the office and make special arrangements while away.

In order to make the system usable on a daily basis for negotiation support, all of the experts agreed that it would need to be easy to use, reliable and readily available.

\subsection{Summary}

The experts all agreed that conducting a negotiation using the augmented collaborative environment was practical. The use of virtual artefacts, if used appropriately, could become common practice in the future for ADR negotiations and more formal legal processes. One expert also observed that since the technology provided a much cheaper and quicker way of conducting ADR negotiations, the cost and availability of the solution would be the only factors that affected the speed with which it would be adopted on a wider basis.

\section{CONCLUSIONS}

This paper has presented an experiment and evaluation of an augmented collaborative environment for supporting ADR negotiations in a geographically distributed environment. The experts who took part in the negotiation were very positive and it is clear that conducting remote ADR negotiations using an augment collaborative environment is a practical solution that could save time and money. It was found that each participant's situation awareness appeared to be higher than would normally be expected for ordinary meetings held using video conferencing. This was found to be largely due to the formal and structured nature of the ADR negotiation, such that turn taking is enforced by the natural order of the proceedings, rather than being forced on the participants by technology shortcomings. The use of virtual artefacts was seen as being important and their use is likely to grow both for remote and face-to-face meetings.
The results were encouraging and contribute to the wider goals of the Court 21 project to study the introduction of new technologies into the legal process, and Courtrooms in particular. However, as indicated by Johnson \& Post [9], many of the issues that could have a major impact on ADR, still need to be investigated and resolved.

\section{ACKNOWLEDGEMENTS}

The authors would like to thank Prof. Frederic Lederer of the Courtroom21 project in William and Mary School of Law, US and Jeremy Barnet and Simon Bickler of CourtCom Ltd in the UK, for their support and participation in this work, and all of the representative from the Crown Prosecution Service and Legal profession who attended the session and provided valuable feedback for the evaluation.

\section{REFERENCES}

[1] Chidambaram, L. (1996). Relational development in computer-supported groups. MIS Quarterly, 20(2), pp 143165.

[2] Damian Herlea, D. E., Eberlein, A., Shaw, M. L.G., Gaines, B. R. (2000) Using Different Communication Media in Requirements Negotiation IEEE Software May/June 2000 (Vol. 17, No. 3) pp. 28-36

[3] Damian D. E., Eberlein A. (2001) An Empirical Study of Groupware Support for Requirements Negotiations in Distributed Software Development, Proceedings of the 2001 ICSE Workshop on Software Engineering over the Internet, Toronto, ON, Canada.

[4] Daft, R. L., Lengel, R. H. (1984). A proposed integration among organizational information requirements, media richness, and structural design. Management Science, 32, pp 554-571.

[5] Fisher, R. (1983) negotiation power: Getting and Using Influence. American Behavioral Scientist, 22(2), pp 149-166.

[6] Gutwin, C. and Greenberg, S. (1995): Support for Group Awareness in Real-time Desktop Conferences. Proceedings 2nd New Zealand Computer Science Research Students' Conference, April 1995.

[7] Hill, R. (1999). On-line Arbitration: Issues and Solutions. Arbitration International, April 1999 issue.

[8] Jackson, M., Anderson, A. H., McEwan, R., Mullin, J. (2000). Impact of video frame rate on communicative behaviour in two and four party groups. Computer Supported Cooperative Work (CSCW 2000), December 2-6, 2000, Philadelphia, PA, USA. ACM, 2000, pp 11-20

[9] Johnson, D. R., Post, D. G. (1996). Law and Borders - The Rise of Law in Cyberspace. 48 Stantford Law Review 1367.

[10] Lederer, F. I. (1997). The courtroom as a Stop on the Information Superhighway, 4 Australian J.L. Reform 71 (1997).

[11] Lederer, F. I. (1999b). The Road to the Virtual Coutroom: Consideration of Today's - and Tomorrow's- High Technology Courtrooms. Six National Court Technology Conference (CTC6), National Center for State Courts, US, September 14-16, 1999. 
[12] LiPera, S. D. (1996). The Impact of New Media: A Model for the Use of Desktop Video Conferencing in Negotiations. Thesis for "The Impact of New Information Resources" (BA 296.7) course taught by Prof. Howard Besser at the Haas School of Business, University of California, Berkeley December 5, 1996. On-line:

http://is.gseis.ucla.edu/impact/f96/Projects/slipera/

[13] Rangaswamy, A., Starke, K. (2000) Computer-mediated Negotiations: Review and Research Opportunities. In Encyclopedia of Microcomputers, Allen Kent and James G. Williams (Eds), Vol. 26, Marcel Inc., NY: New York.

[14] Rockwell, P. (1999). The Effect of Attorneys' Nonverbal Communication on Perceived Credibility. The Journal of Credibility and Assessment and Witness Psychology, 2(1), pp 1-13.
[15] Sherfey, P. L. (2000). The Road to a Paperless Court. Washington State Bar News, May 2000. On-line: http://www.wsba.org/barnews/2000/05/sherfey.htm

[16] Starke, K. (1999) Computer-mediated Negotiations: Review and Research Opportunities. E-Business Research Centre (eBRC) Working Paper, 5-2000. On-line: www.ebrc.psu.edu/publications/papers/pdf/2000-05.pdf

[17] Turletti, T. Huitema, C. (1996). Video conferencing on the Internet. IEEE/ACM Trans. on Networking, 4(3), pp340351, June 1996.

[18] M. Thompson, J. Maxfield and P.M. Dew, Interactive Virtual Prototyping, In Proc. of Eurographics UK '98, pp107 